\title{
Bridging internet and cultural heritage through a digital marketing funnel: An exploratory approach
}

\section{Călin Vegheș}

Department of Marketing, Bucharest University of Economic Studies, Romania.

\begin{abstract}
Digital marketing and cultural heritage: what may have in common two areas that seem so different? What may connect a dynamic, evolving and even catchy field to a rather static, outdated and quite boring one? Maybe a funnel. Actually, a marketing funnel. More precisely a digital marketing funnel aiming to support the capitalization of the cultural heritage by drawing attention, raising interest, stimulate desire and generate action related to the cultural heritage output - goods, services, brands, events, and activities - under of the forms of discovering, exploring, experiencing and enjoying this heritage. Using secondary data regarding the cultural heritage in the European Union, the paper investigates the connections between the usage of the internet for cultural heritage purposes, different forms of consumption of the cultural heritage, and main barriers limiting this consumption and illustrates that building and employment of a digital marketing funnel is indispensable in the capitalization of the cultural heritage.
\end{abstract}

Keywords: digital marketing; cultural heritage; marketing funnel. 


\section{Introduction}

The definition issued by the ICOMOS International Cultural Tourism Committee (2002) sees the cultural heritage as the expressions of the ways of living developed by a community and passed on from generation to generation, including customs, practices, places, objects, artistic expression and values taking tangible (places of human habitation, villages, towns, and cities, buildings, structures, artworks, documents, handicrafts, musical instruments, furniture, clothing and items of personal decoration, religious, ritual and funerary objects, tools, machinery and equipment, and industrial systems) or intangible (all forms of traditional and popular or folk culture, the collective works originating in a given community and based on tradition - oral traditions, customs, languages, music, dance, rituals, festivals, traditional medicine and pharmacopeia, popular sports, food and the culinary arts and all kinds of special skill connected with the material aspects of culture) forms.

Researching the cultural heritage from a marketing perspective requires, besides this almost exhaustive and heritage experience-oriented vision, a more structured framework describing the cultural heritage market and related heritage consumption behavior. The European Commission (2017) has structured the cultural heritage market in libraries and archives; historical monuments and sites; museums and galleries; traditional events; traditional craft workplaces; cinema or film heritage festivals; traditional or classical performing arts events.

As the data of the Special Eurobarometer 466 reveals, the cultural heritage consumption of the European consumers is rather modest in spite of an overall context in which access to culture implying the consumption of various cultural goods and services by the public at large represents an opportunity to benefit from the cultural offer (Pasikowska-Schnass, 2017). Besides the demographical, economic, social or even... cultural reasons, the modest level of cultural heritage consumption can also be the result of the rare and less effective marketing campaigns conducted to convince the European consumer to discover, explore, experience and enjoy this heritage. What seems to be missing is a marketing funnel designed considering, on a hand, the stages of heritage cycle proposed by Thurley (2005) - understanding, valuing, caring for and, finally, enjoying, and, on the other hand, the classical stages of the AIDA model - attention, interest, desire, and action in connection to the cultural heritage.

In a context in which, on a hand, culture tends to become the fourth pillar of the sustainable development and culturally sustainable development adequately encompasses all the meanings of culture and all its complex interactions with the social, economic and environmental dimensions of human life (Sabatini, 2019), and, on the other hand, digital technologies are rapidly changing the environment by reducing information asymmetries between customers and sellers, and significantly changing the consumer behavior (Kannan and $\mathrm{Li}, 2017$ ), designing a digital marketing funnel appears as the best way to promote and capitalize the cultural heritage consumption. Observing the increasing prevalence of digital 
media and tools in marketing, Leeflang et al. (2014) have identified three major digital changes, such as the ability to interact with and/or serve customers in a new manner, increasing access to data and insights, and the ability to reach new customer segments that be considered in the design process. Going beyond digital customers' acquisition and retention, Eigenraam et al. (2018) have developed a taxonomy of customers' digital brand engagement practices to integrate ample research about such digital practices, and to standardize these digital practices across digital channels and platforms including five different types engagement practices (fun, learning, giving feedback, talk about and work for a brand) with corresponding tools. Integrating the digital component in the marketing funnel may improve the content and effectiveness of the marketing efforts conducted by the cultural heritage organizations addressing increasingly connected audiences in terms of facilitating discovery, exploration, experiencing and enjoying the cultural heritage.

\section{Methodological notes}

Data from the Special Eurobarometer 466 on Cultural Heritage (2017) have been considered in order to measure the ways in which European consumers have used the Internet for cultural heritage purposes, the frequency with which they attended cultural heritage-related activities and the main barriers encountered experiencing cultural heritage.

The variables of the research have been defined preserving the original format described in the Special Eurobarometer 466, as it follows:

1. Internet usage (IU), with the following sub-variables: IU0 - At least one cultural heritage related purpose; IU1 - Looking up general information related to cultural heritage, such as the accessibility, facilities and main features of a museum, historical monument, or traditional event in preparation for a visit or your holidays; IU2 - Buying or booking services for events or activities, such as tickets, guided tours, etc.; IU3 - Viewing cultural heritage-related content, such as the description of a work of art or historical monument during a visit, historical information about a traditional event you attend, etc.; IU4 - Creating or sharing cultural heritage-related content, such as a picture or a video of a work of art or historical monument, etc.; IU5 - Knowing more about a museum or a traditional festival, historical monuments, exhibition after a visit; and IU6 - Giving opinions of a cultural heritage site or activity (e.g. comments or scores on a review website).

2. Cultural heritage consumption forms (HC), with the following sub-variables: HC1 Visited a library or archive (e.g. to consult manuscripts, documents, ancient maps, etc.); HC2 - Visited a historical monument or site (palaces, castles, churches, archaeological sites, gardens, etc.); HC3 - Visited a museum or gallery; HC4 - Attended a traditional event (e.g. food festival, carnival, puppet theatre, floral festival, etc.); HC5 - Visited a traditional craft workplace (e.g. weaving, glass blowing, decorative art, embroidery, making musical 
instruments or pottery, etc.); HC6 - Been to the cinema or a film heritage festival to see a classic European film produced at least 10 years ago; and HC7 - Seen a traditional or classical performing arts event (e.g. music, including opera, dance or theatre, folk music, etc.).

3. Main barriers in experiencing cultural heritage (MB), with the following sub-variables: MB1 - Lack of interest; MB2 - Lack of time; MB3 - Cost; MB4 - Lack of information; MB5 - Lack or limited choice of cultural heritage sites or activities in the area; MB6 - Poor quality of cultural heritage sites or activities in the area; and MB7 - Cultural heritage sites or activities are too remote or difficult for you to access.

Associations between internet usage and frequency of attending cultural heritage-related activities, respectively internet usage and main barriers in experiencing cultural heritage have been measured using the Pearson correlation coefficient.

\section{Main results}

More than half (55\%) of the European consumers have used the internet for cultural heritage related purposes which may suggest a relatively sound presence of the network of networks in the daily life of the European cultural heritage consumer. At a more careful evaluation, there are two areas requiring significant improvements: the differences between the European countries, respectively the purposes of this usage. There is a large spread of the internet usage for cultural heritage purposes frequency: from $24 \%$ (Portugal), $37 \%$ (Greece) and $41 \%$ (Bulgaria) to $83 \%$ (Netherlands), $84 \%$ (Belgium) or $85 \%$ (Sweden). There are also significant differences in terms of the purposes: almost a third $(31 \%)$ of the European consumers use internet to prepare a visit or a holidays by looking up general information related to cultural heritage, about one in five use it to buy or book related services $(23 \%)$, view cultural heritage-related content experiencing or preparing the experience (21\%), know more about a cultural heritage site or event after experiencing (19\%), and around one in ten use it to create or share cultural heritage-related content $(11 \%)$ or give their opinion of a cultural heritage site or activity $(6 \%)$.

Still, the internet usage supports the consumption of cultural heritage (see Table 1): using internet for at least one cultural heritage related purpose associates significantly $(\mathrm{p}<.001)$ and positively with the specific forms of consumption represented by visiting a traditional craft workplace, a museum or gallery, a library or archive, a historical monument or site, and seeing a traditional or classical performing arts event. Positive, less intense and not statistically significant associations have been measured in the cases of going to a cinema or film heritage festival and attending traditional events. The internet proves to be supportive to the public of the traditional craft workplaces, museums and galleries, libraries and archives, historical monuments and sites, and traditional or classical performing arts events, and rather informative to the audiences of film heritage festivals and/or traditional events. 
Table 1. Measures of associations between the usage of the internet and forms of cultural heritage consumption in the European Union.

\begin{tabular}{|c|c|c|c|c|c|c|c|}
\hline & IU0 & IU1 & IU2 & IU3 & IU4 & IU5 & IU6 \\
\hline \multirow{2}{*}{ HC1 } & $0.765 * * *$ & $0.800 * * *$ & $0.801 * * *$ & $0.720 * * *$ & $0.563 * *$ & $0.738 * * *$ & $0.505 * *$ \\
\hline & $<.001$ & $<.001$ & $<.001$ & $<.001$ & 0.002 & $<.001$ & 0.006 \\
\hline \multirow{2}{*}{ HC2 } & $0.744 * * *$ & $0.875 * * *$ & $0.856 * * *$ & $0.812 * * *$ & $0.623 * * *$ & $0.779 * * *$ & $0.484 * *$ \\
\hline & $<.001$ & $<.001$ & $<.001$ & $<.001$ & $<.001$ & $<.001$ & 0.009 \\
\hline \multirow{2}{*}{ HC3 } & $0.847 * * *$ & $0.908 * * *$ & $0.932 * * *$ & $0.864 * * *$ & $0.691 * * *$ & $0.819 * * *$ & $0.542 * *$ \\
\hline & $<.001$ & $<.001$ & $<.001$ & $<.001$ & $<.001$ & $<.001$ & 0.003 \\
\hline \multirow{2}{*}{ HC4 } & 0.291 & 0.361 & 0.357 & 0.222 & 0.186 & 0.215 & 0.288 \\
\hline & 0.133 & 0.059 & 0.062 & 0.256 & 0.345 & 0.271 & 0.137 \\
\hline \multirow{2}{*}{ HC5 } & $0.820 * * *$ & $0.837 * * *$ & $0.867 * * *$ & $0.774 * * *$ & $0.633 * * *$ & $0.783 * * *$ & $0.589 * * *$ \\
\hline & $<.001$ & $<.001$ & $<.001$ & $<.001$ & $<.001$ & $<.001$ & $<.001$ \\
\hline \multirow{2}{*}{ HC6 } & $0.524 * *$ & 0.290 & $0.470^{*}$ & 0.310 & 0.252 & 0.317 & 0.283 \\
\hline & 0.004 & 0.135 & 0.012 & 0.109 & 0.195 & 0.100 & 0.145 \\
\hline \multirow{2}{*}{ HC7 } & $0.661 * * *$ & $0.706 * * *$ & $0.766 * * *$ & $0.639 * * *$ & $0.482 * *$ & $0.635 * * *$ & $0.506^{* *}$ \\
\hline & $<.001$ & $<.001$ & $<.001$ & $<.001$ & 0.009 & $<.001$ & 0.006 \\
\hline
\end{tabular}

Internet usage also stimulates the frequency of experiencing different forms of cultural heritage. Using more intensely the internet for at least one cultural heritage related purpose associates significantly $(\mathrm{p}<.001)$ and positively with the frequency of visiting museums and galleries, historical monuments or sites, seeing traditional or classical performing arts events, and visiting libraries or archives. The internet is supportive but not influencing significantly the frequency of experiencing in the cases of visiting traditional craft workplaces, going to the cinema or a film heritage festivals or attending traditional events.

The digital marketing funnel works almost perfectly (a significant association of $\mathrm{p}<.001$ for all six ways of internet usage) in the case of experiencing traditional craft workplaces. The public looks up for general information related to the accessibility, facilities and main features of these traditional craft workplaces and, particularly, to buy or book the related cultural heritage output - goods, services, brands, events or activities. The Internet is also used to improve the experience by knowing more about the traditional craft workplaces after and viewing related content during the visit. The Internet is least yet significantly used to 
create or share content and give post-experience opinions about the related heritage content. Visiting historical monuments or sites, as well as museums or galleries, have the same pattern of internet usage. Heritage consumers interested in palaces, castles, churches, archaeological sites, gardens, museums, and galleries employ the internet to look up general information related to the sites they are about to experience during their visits or holidays and/or to buy or book related cultural heritage output. They add value to their experiences by accessing and viewing cultural heritage-related content during their visits and improve them by getting more information about the sites after the visit. The Internet is less used to create or share cultural heritage-related content and to give opinions about heritage sites or activities.

Visiting libraries or archives and seeing traditional or classical performing arts events reveal a slightly different pattern of internet usage. Their public use the internet to looking up general information related to the cultural heritage content they would like to experience, buy or book specific cultural heritage output, access related content to during experiencing the heritage and knowing more about the heritage entity and/or content after experiencing it. The Internet is less used to create and share cultural heritage-related content or to give opinions about cultural heritage sites or activities.

The digital marketing funnel seems less relevant to the heritage consumers interested in going to cinema or film heritage festivals and, particularly, attending traditional events. Internet is used to look up information related to the such as cinema, film or food festivals, carnivals, puppet theatres, floral festival, buying or booking specific cultural heritage output, viewing cultural heritage-related content during experiencing or knowing more about this heritage after experiencing, creating or sharing later cultural heritage-related content or even giving opinions about cultural heritage sites or activity, but its employment does not associates significantly with the consumption of these forms of cultural heritage. The exception from the rule is represented by the buying or booking related cultural heritage output in the case of cinema or a film heritage festivals.

The barriers invoked by the nine out of ten heritage consumers explain the modest cultural heritage consumption in the European Union. According to the Special Eurobarometer 466 (2017), lack of time (indicated by $37 \%$ of the European consumers), cost (34\%), and lack of interest $(31 \%)$ together with the lack of information (25\%) completes the harmful set of factors reducing significantly the willingness to discover, explore, experience and enjoy a somehow worthless, somewhat expensive, rather unknown and boring enough heritage. Lack or limited choice $(12 \%)$, remoteness $(12 \%)$, and poor quality $(6 \%)$ of the cultural heritage sites are peripheral but reinforcing reasons of the reserved attitude towards the cultural heritage related opportunities.

Can a digital marketing funnel soften these barriers and improve the consumption of cultural heritage? Measures of the associations between internet usage and main barriers of the 
cultural heritage consumption (see Table 2) suggest a partially positive answer.

Table 2. Measures of associations between the usage of the internet and barriers of cultural heritage consumption in the European Union.

\begin{tabular}{|c|c|c|c|c|c|c|c|}
\hline & IUN & IU1 & IU2 & IU3 & IU4 & IU5 & IU6 \\
\hline \multirow{2}{*}{ MB1 } & -0.214 & $-0.384^{*}$ & -0.249 & -0.310 & -0.205 & -0.322 & -0.283 \\
\hline & 0.274 & 0.043 & 0.201 & 0.109 & 0.296 & 0.095 & 0.144 \\
\hline \multirow{2}{*}{ MB2 } & 0.215 & 0.182 & 0.154 & 0.169 & -0.030 & 0.285 & -0.076 \\
\hline & 0.271 & 0.354 & 0.435 & 0.390 & 0.880 & 0.142 & 0.700 \\
\hline \multirow{2}{*}{ MB3 } & $-0.480 * *$ & $-0.608 * * *$ & $-0.580 * *$ & $-0.614 * * *$ & $-0.593 * * *$ & $-0.521 * *$ & $-0.459 *$ \\
\hline & 0.010 & $<.001$ & 0.001 & $<.001$ & $<.001$ & 0.004 & 0.014 \\
\hline \multirow{2}{*}{ MB4 } & -0.105 & -0.259 & -0.110 & -0.128 & -0.115 & 0.013 & 0.043 \\
\hline & 0.594 & 0.184 & 0.578 & 0.517 & 0.561 & 0.949 & 0.828 \\
\hline \multirow{2}{*}{ MB5 } & -0.341 & $-0.448 *$ & -0.312 & -0.363 & -0.250 & -0.301 & -0.113 \\
\hline & 0.076 & 0.017 & 0.106 & 0.058 & 0.200 & 0.119 & 0.566 \\
\hline \multirow{2}{*}{ MB6 } & $-0.407 *$ & $-0.565 * *$ & $-0.462 *$ & $-0.472 *$ & -0.239 & $-0.450 *$ & 0.028 \\
\hline & 0.032 & 0.002 & 0.013 & 0.011 & 0.221 & 0.016 & 0.889 \\
\hline \multirow{2}{*}{ MB7 } & -0.150 & -0.141 & -0.040 & -0.106 & -0.197 & 0.042 & 0.189 \\
\hline & 0.447 & 0.475 & 0.839 & 0.592 & 0.316 & 0.832 & 0.336 \\
\hline
\end{tabular}

Using the internet to obtain relevant, sufficient, and attractive general information about the cultural offer and the cultural heritage output could significantly reduce the barriers of costs, poor quality, lack or limited choice and lack of interest. Buying or booking cultural heritage output, viewing related content during experiencing as well as knowing more about the cultural heritage related content after experiencing it, may significantly diminish the barriers represented by the cost and poor quality of the heritage sites supporting the feeling that the experience was worth it and provided a good value for money. Last but not least, creating or sharing cultural heritage-related content and giving opinions about a cultural heritage site or activity may also diminish the barrier represented by the cost associated with experiencing the cultural heritage. Cost appears as a common denominator for all the purposes of using the internet in connection with cultural heritage. 


\section{Conclusions}

Given the extent of the internet access and usage, costs of running online communication campaigns, and comfort of interacting online with the consumers, providing online information and support about the organization and its products, services, brands, events or activities is the most obvious, convenient, but also simple way to connect to its public. Cultural entities make no exception from this evidence and perhaps the most important conclusion of this study is that the internet "does well" to the consumption of cultural heritage outputs: more internet means more cultural heritage consumption and integrating a digital component into the marketing funnel is a must.

Considering the stages to be developed in order to support the market presence of the cultural heritage output (discovery, exploration, experience and enjoy), the digital component of the marketing funnel seems to impact significantly all mostly by limiting the barriers of cultural consumption, especially the price. In fact, not the price in itself, but the value for money (and time!) received and appreciated as such by the heritage consumer. Although it may sound too commercial, we need to understand that all the commodities providers (including of cultural heritage output), compete nowadays for the budget and time of each consumer and designing and employing a marketing funnel with a consistent digital component is the most effective solution for the capitalization of the cultural heritage.

\section{References}

Eigenraam, A. W., Eelen, J., van Lin, A., Verlegh, P. W. J. (2018). A Consumer-based Taxonomy of Digital Customer Engagement Practices. Journal of Interactive Marketing, 44, 102-121.

European Commission (2017). Special Eurobarometer 466 - October 2017 Cultural Heritage Report. Retrieved from http://ec.europa.eu/commfrontoffice/publicopinion/index.cfm/ResultDoc/download/Doc umentKy/80882.

International Council on Monuments and Sites. ICOMOS International Cultural Tourism Committee (2002). ICOMOS International Cultural Tourism Charter. Principles And Guidelines For Managing Tourism At Places Of Cultural And Heritage Significance. Retrieved from http://www.icomos.no/wp-content/uploads/2014/04/ICTC-Charter.pdf.

Kannan, P. K., Li, H. A. (2017). Digital marketing: A framework, review and research agenda. International Journal of Research in Marketing, 34, 22-45.

Leeflang, P. S. H., Verhoef, P. C., Dahlström, P., Freundt, T., (2014). Challenges and solutions for marketing in a digital era. European Management Journal, 32, 1-12.

Pasikowska-Schnass, M. (2017). Access to culture in the European Union. Retrieved from https://pagina.jccm.es/europa/pdf/PUBLICACIONES/2017\%20access\%20to\%20culture \%20EU.pdf. 
Sabatini, F. (2019). Culture as fourth pillar of sustainable development: Perspectives for integration, paradigms of action. European Journal of Sustainable Development, 8 (3), 31-40.

Thurley, S. (2005). Into the future. Our strategy for 2005-2010. Conservation Bulletin, 49, 26-27. 